\title{
Modular Segmented Motor for Power-Assist Wheelchairs: Proof of Concept
}

\author{
Ilya A. Galkin * ${ }^{\mathbb{D}}$, Rahims Geidarovs and Andrejs Podgornovs \\ Faculty of Electrical and Environmental Engineering, Riga Technical University, LV 1048 Riga, Latvia; \\ rahims.geidarovs@rtu.lv (R.G.); andrejs.podgornovs@rtu.lv (A.P.) \\ * Correspondence: gia@eef.rtu.lv
}

Citation: Galkin, I.A.; Geidarovs, R.; Podgornovs, A. Modular Segmented Motor for Power-Assist Wheelchairs: Proof of Concept. Machines 2021, 9 , 227. https://doi.org/10.3390/ machines 9100227

Academic Editors: Fu-Cheng Wang, Chih-Cheng Lu, Sendren Sheng-Dong $\mathrm{Xu}$ and Wei-Jiun Su

Received: 11 August 2021

Accepted: 30 September 2021

Published: 6 October 2021

Publisher's Note: MDPI stays neutral with regard to jurisdictional claims in published maps and institutional affiliations.

\begin{abstract}
This paper presents an analysis of the opportunity to increase the price availability of small electric vehicles, such as electric scooters, such as bicycles and wheelchairs, by applying expandability and modularity principles to their motors. Assuming that, in many cases, small electric vehicles are brought to the market in several power/price versions, the authors of this report evaluate the possibility of combining different numbers of electromechanical modules while, at the same time, maintaining the unity of the entire drive/motor scheme, thus making the mentioned expandability possible. Power-assist wheelchairs are taken as an example of the application, where such expandability is reasonable. The application provides a price reduction for the less powerful wheelchairs in the case of less severe disabilities. To start, the authors briefly compare multidrive schemes that ground the principle of modularity at the electromechanical level. Then, they outline a radially segmented motor concept and discuss this concept using the example of a permanent magnet synchronous motor. In particular, they propose a methodology for the calculation of its parameters and calculate the particular design details of such a motor. The motor is then analyzed with the help of its mathematical model, as well as experimentally. This tentative evaluation of two $50 \mathrm{~W}$ segments (of a $300 \mathrm{~W}$ 6-segment motor) proves that the proposed segmented modularity concept is feasible, and that it requires a more detailed consideration of the parameters and the other implementation aspects (power driver, control, cooling) of the given synchronous motor. Moreover, the concept might be successfully utilized in the designs of other motor types.
\end{abstract}

Keywords: electric vehicles; intelligent vehicles; wheelchairs; modular construction; AC motors; permanent magnet motors

\section{Introduction}

On one hand, the technological, political, and societal tendencies of recent years require a reduction in the consumption of fossil fuels [1]. However, on the other hand, these tendencies creates higher mobility in people [2]. This has led to rapid progress in the field of all-electric vehicles (EVs) [3,4] with regard to the appearance and development of new small EV types, such as electric mini-scooters and power-assisted electric bicycles [5], as well as the appearance of new transport services, such as rental scooters. Similar to the traditional vehicles with internal combustion engines, EVs are often supplied to the market in several versions [6], with electric motors of different power ratings that, however, do not significantly affect the scheme of the entire power train and, finally, the price of the vehicle. In some cases of small EVs, such as the case of power-assist wheelchairs, this peculiarity reduces the price availability of such EVs and leads to negative social impacts. The main challenge of this work is to provide energetically and economically scalable electrical motors to weaken these negative impacts and, possibly, to provide new EV services.

The scientific and technical novelty of this work is concentrated in the field of electrical machines. The proposed electromechanical configuration, in fact, implements a multimotor drive at the level of the synchronous electrical machine. The proposed idea is technically described, and tentatively verified by means of simulation and experiment. 


\subsection{Characterisation of Wheelchair Users}

An analysis of the current statistics in the field of disability is presented in [7], but its simplified version can be found in [8]. Below, the most significant considerations of this analysis are provided. According to the data of the World Health Organization (WHO), about three hundred million people undergo difficulties during movement [9]. These people have different origins of their disability (illness, ageing, or weight), its features, and personal peculiarities. From the perspective of function, it is possible to emphasize the following categories of wheelchair users: (1) persons who can continuously drive their wheelchairs applying their own muscle power; (2) persons who can do it only temporarily, but can continuously control them, utilizing some direct means, for example, a joystick or pushbuttons; and (3), persons who not only cannot continuously power the wheelchairs by their own muscle power, but cannot control them directly. The actual utilization of the wheelchairs is also influenced by the motivation of their users to avoid technical assistance as much as possible, considering that the international [9], US [10], and European [11] reports on disability show that there exists a significant number of such persons. Finally, the dynamic profile of the disability is important. Besides the constant disability, the progressive reduction of these occasions must be taken into account. On these occasions, the demand in technical assistance tools also changes, even with the similar motivation to use their own power.

Therefore, the conclusion following from the above-mentioned states is that these kinds of small EVs may require motors with a very different power rating.

\subsection{Overview of Wheelchair Types, Present on Market}

Four distinct types of wheelchairs (Figure 1) are typically emphasized in the overviews [12] of these vehicles. The first one is the type of manually powered wheelchair, low-weight, rather compact, non-foldable, and inexpensive devices. However, they are suitable only during rehabilitation and for the limited ranges of disabled persons. The wheelchairs of another type utilize electric drives to support motion and direct the control means (such as joysticks) for the purposes of control [13]. These wheelchairs are identified as electric-powered. They are suitable for more disabled persons but, at the same time, are heavy, bulky, and expensive. Further development of the electric-powered wheelchairs produced a special type of power-assist wheelchair [14]. The main features of the powerassist wheelchairs are the motored-hubs of the motor-wheels, which operate as torque amplifiers. These wheelchairs are light and portable, but even more expensive [15]. Finally, the fourth type of wheelchair is known as a smart wheelchair, decision-making systems or, in fact, autonomous robotic vehicles. It can be observed that the common feature of these wheelchairs is their fixed configuration. This forms a gap between the "low end" and "high end" segments of the wheelchair market and can cause people with limited disability to overpay. This consideration is particularly important in the case of a progressive and reducing disability, where the obtainment of a completely new wheelchair is necessary.

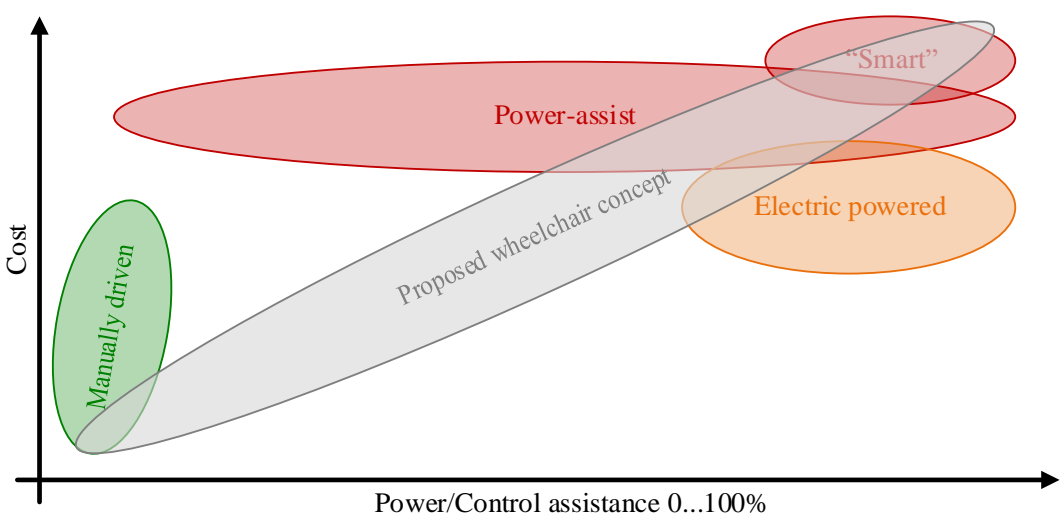

Figure 1. Cost availability of the wheelchairs presently on the market. 
Additionally, the designers of power-assist wheelchairs face the following challenges from user requirements:

- Variable levels of assisting, meaning that some wheelchair users require full-motion power from their wheelchair (full assistance), while other users, who are able to move the wheelchair with their own muscular power, require only some additional power for ease of movement or in difficult places.

- In the case of full assistance, wheelchair control is achieved by the joystick method, etc. In the case of partial assistance, wheelchair control is provided, to a greater or lesser extent, by the muscular strength of the user. Some kind of torque sensing and amplification is required that is obviously easier to do in an electrical machine.

- The upper mass limit of the user of the designed wheelchair is defined as $120 \mathrm{~kg}$. With this mass, the wheelchair electric drive system works most efficiently. However, the vast majority of wheelchair users do not achieve this mass limit. Therefore, it is necessary to make the wheelchair as efficient as possible for masses under $120 \mathrm{~kg}$.

Trying to fix the above-mentioned problems, and fulfill the corresponding societal requests, the authors of this work proposed a concept for a cost-effective power-assist wheelchair, with a price that drops together with the real level of disability.

\subsection{Modifying Power Drive Train for Better Cost Availability}

The total cost of power-assist wheelchairs depends a lot on the cost of its electrical motor and its power electronic driver, on its battery pack and charger, as well as on the control system. Respecting the principle, "price drops with disability", requires that less disabled persons can obtain a less powerful version of the wheelchair at a lower price. On the other hand, a unified hardware platform facilitates lower prices for a series of wheelchairs. Moreover, the dynamically changing (progressive or reducing) disability requests that the overall scheme of the wheelchair, and its subsystems, remains the same for easier expansion/reduction. Therefore, the technical challenge is to change the power level without significantly changing the hardware.

The above-mentioned functional and technical problems can be solved by applying modular technology. Modular technology, in this case, means that the wheelchair's electric drive system is split into modules, the parts of the system that are essentially a system analogue that can operate autonomously from, or interlink with, other similar modules. The main difference between the drive module and the drive system, in this case, is that the power of one module is $n$ times less than the power of the whole system, where $n$ is the number of modules. Thus, by varying the number of modules used in a wheelchair, it is possible to adjust the maximal level of required assistance. When the required number of modules is smaller, this also allows for fitting the particular wheelchair to a particular mass, and for achieving cost-effectiveness. This report is focused on such modularity applied to an electrical motor.

One of the possible configurations of multiple motor drives assumes that all the motors are connected mechanically through the individual transmission (Figure 2a). It facilitated the installation and the removal of extra motors, which can be standard motors available on the market. On the other hand, this configuration has additional power losses in the transmissions, and a higher price at higher powers (if one compares it with a single motor).

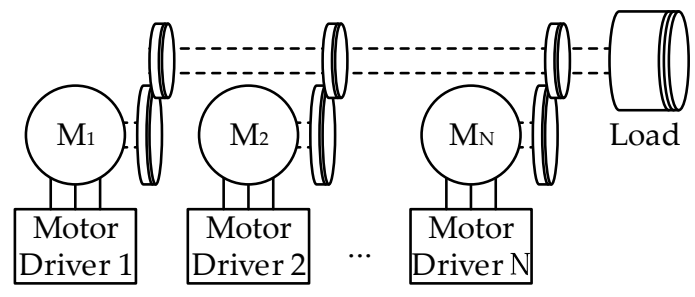

(a)

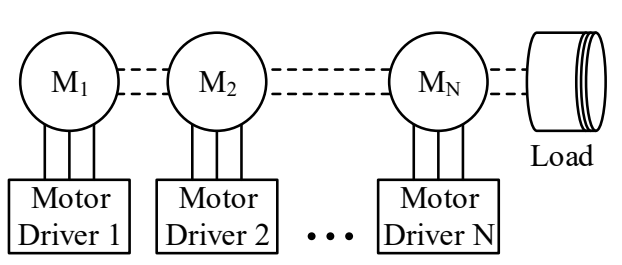

(b)

Figure 2. Configurations of multiple motor drive: (a) with multiple transmissions; (b) with single shaft. 
The most direct alternative is the hard mechanical connection of multiple motors to the single load and shaft (Figure 2b). The direct implementation of this scheme assumes that the rotors of several motors are attached on the same shaft that drives the load (Figure 3a). This configuration has much better energy efficiency and dynamic performance, but wheelchairs, as well as other vehicles, such as bicycles, require that the motors are "flat", which makes them mechanically fragile, but makes their electromechanical characteristics worse. Therefore, it seems that the most promising configuration has the same rotor and shaft, magnetically coupled with several stator segments (Figure 3b) [16]. Below, the authors of this paper adopt this configuration to the fit the needs of configurable power-assist wheelchairs and analyze its feasibility in this case.

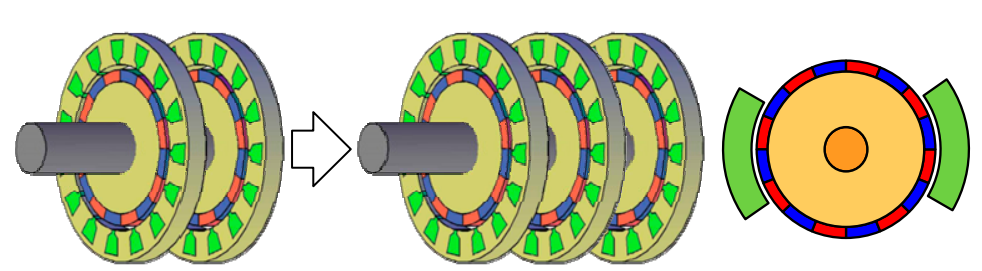

(a)

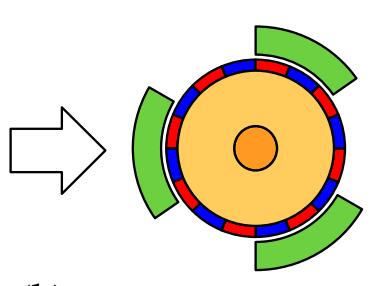

(b)

Figure 3. Single shaft multiple motor drive: (a) axial connection of motors, 2 motors vs. 3 motors; (b) sectional motor, 2 segments vs. 3 segments.

\section{Motor Requirements for Electric-Powered and Power-Assist Wheelchairs}

The speed of electric-powered wheelchairs typically does not exceed $v_{\max }=15 \mathrm{~km} / \mathrm{h}$, which is also the reasonable safety limitation stated in the standard ISO 07176 (Table 1).

Table 1. Main operation parameters of the wheelchair.

\begin{tabular}{|c|c|c|c|}
\hline Symbol & Quantity & Source & Value \\
\hline$v$ & Cruise speed (>70\%) & ISO07176 & $5 \mathrm{~km} / \mathrm{h}=1.4 \mathrm{~m} / \mathrm{s}$ \\
\hline$v_{\max }$ & Maximal speed & ISO07176 & $15 \mathrm{~km} / \mathrm{h}=4.2 \mathrm{~m} / \mathrm{s}$ \\
\hline$m$ & $\begin{array}{l}\text { Full mass of the wheelchair } \\
\text { and its user }\end{array}$ & Design parameter & $120 \mathrm{~kg}$ \\
\hline$f$ & $\begin{array}{c}\text { Coefficient of rolling } \\
\text { resistance (rubber-concrete) }\end{array}$ & Design parameter & $15 \ldots 35 \mathrm{~mm}$ \\
\hline$D_{w h}$ & Wheel diameter & Design parameter & $660.4 \mathrm{~mm}$ \\
\hline
\end{tabular}

In real environments, in particular, if the wheelchair performs a power-assisting function, this speed is much lower. If the wheelchair utilizes standard wheels of a diameter $D_{w h}$, equal to 26 inches, or $660.4 \mathrm{~mm}$, then the rotational speed of the machine rotor per minute can be determined as:

$$
n_{\text {max }}=\frac{v_{\text {max }} \times 1000 \times 60}{3600 \times \pi \times D_{w h}}=132 \mathrm{~min}^{-1},
$$

The value $132 \mathrm{~min}^{-1}$ following from (1) shows that the requested machine is a lowspeed machine, either a brushless direct current machine (BLDC machine), or a permanent magnet synchronous machine (PMSM). A PMSM is preferable because it is simpler in manufacturing and has better dynamic performance in terms of rapid changes in the control signals, making the wheelchair more maneuverable. An alternative, an asynchronous machine, has not been considered in this study as it is potentially less energy-efficient in spite of the potential benefit of better-starting torque. Another alternative, the switched reluctance machine, has not been evaluated because of its more complicated rotor and power electronic driver, mandatory for its operation. The above-mentioned alternatives can be considered as topics for the further industrial evaluation of the same concept. 
The maximal power of the motor can be extracted from the basic operational parameters of the wheelchair. In cruise mode, the power can be defined as the product of the rolling resistance, $F_{t}$, and cruise speed, $v$, at which this rolling resistance takes place:

$$
P_{t}=F_{t} \times v .
$$

The first parameter of (2) can be reached of the following equilibrium of forces:

$$
\left|\overrightarrow{F_{t}}\right| \times R_{w h}=|\vec{N}| \times f \text { or } F_{t}=N \times f / R_{w h}
$$

assuming that $N$ is the gravitation force vertically applied to the mass, and $R_{w h}=D_{w h} / 2$-is the radius of the wheel and the $f$-coefficient of rolling resistance, which depends on the materials of the surface and the wheel. Taking into account the definition of the gravitational force, $m g$, the number of wheels, $N_{w h}=2$, that take the wheelchair weight, as well as assuming that the mass of the wheelchair is $m,(2)$ can be transformed to:

$$
F_{t}=\frac{f}{R_{w h}} \times \frac{m \times g}{N_{w h}} .
$$

Utilizing (4), with the real parameters from Table 1, gives the value of cruise power at about $37 \ldots 85 \mathrm{~W}$. The maximal power applied during the acceleration also corresponded to the maximal speed. Taking into account the tentative energy efficiency of the motor of $75 \%$, its electric power must be from 50 to $350 \mathrm{~W}$ to provide the required torque moment for the wheelchair. Hereafter, a $300 \mathrm{~W}$ prototype is considered.

The adjustment of the rated power of the wheelchair is provided by add/remove stator arc-shaped armature elements. The symmetrical operation of the wheelchair requires that the same mechanical power of each armrest module is equal. Then, taking into account the technical specifications of the wheelchair, and the upper limit of the user's weight of $100 \mathrm{~kg}$, as well as the self-mass of the wheelchair of $20 \mathrm{~kg}$, the weight-step is defined as $20 \mathrm{~kg}$ per arc-shaped element, but the number of the motor modules that allowed a variety of stator configurations was six (Figure 4). The maximal output power and torque are obtained using all six arc-shaped elements of the stator.
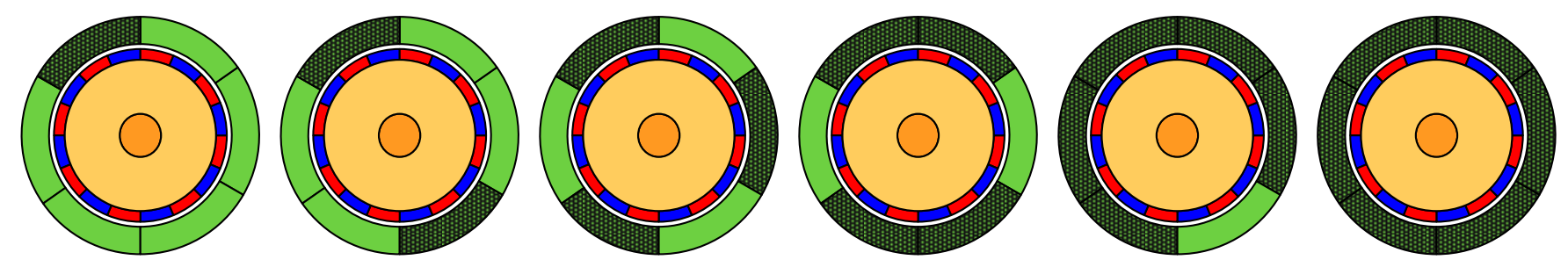

Figure 4. Possible configurations of segmented arc-shaped stator elements, at total number of segments, equal to 6 .

\section{Concept of Segmented Modular PMSM}

\subsection{Generalized Description of Concept}

The concept of a novel modular PMSM proposes the division of the stator into several arc-shaped modules or segments. An example, with the total number of the segments equal to six, is explained in Figure 4. At such a number of segments, there are 90 slots in the stator, and it can be easily divided with the number of phases, $m=3$. Each module can act as a separate three-phase stator. The stator is made of unbalanced three-phase concentrated fractional slot winding with the total number of slots (for six modules), $Z=90$. In this case, the number of slots for one module is 15 . The rotor is made of $72 \mathrm{NdFeB}$ permanent magnets (PMs) with a radial magnetization. That choice of PMs gives an advantage to the creation of a strong excitation field. The prototype model, shown in Figure 2, is made with 
the unbalanced three-phase winding system. Additionally, it provides an opportunity to investigate the nonsymmetrical modes of modular PMSMs.

\subsection{Calculation of Main Parameters of Armature Slots}

This section presents the mathematical model, suitable for calculating the design parameters of a single segment, the geometrical dimensions, the number of turns per section, etc. The full-wave $120^{\circ}$ computation method has been chosen as the basis for this model, assuming that the distribution of the magnetic flux is sinusoidal. Then, the number of turns per section can be expressed as:

$$
W_{s e c}=\frac{5.75 E_{a v e r}}{p \times n \times k_{w} \times \Phi}
$$

where $E_{\text {aver }}$ is the averaged electromotive force of the stator; $p$ is the doubled number of poles of the magnetic field; $n$ is the speed of rotation (repetition per minute); $k_{w}$ is the density of winding; and $\Phi$ is the magnetic flux. The magnetic flux $\Phi$ in (5) requires knowledge of the flux density $B_{\delta}$ :

$$
\Phi=\alpha_{\delta} \times B_{\delta} \times l_{\delta} \times \tau .
$$

The particular set of parameters gives the value $\Phi=0.164 \mathrm{mWb}$.

The successful application of finite element methods (FEMs) to field calculation, as well as the use of FEM software, requires the knowledge of the current density in the stator windings, which can be found as:

$$
j_{s}=\frac{(10 \ldots 17) \times 10^{4}}{A} q \prime,
$$

where the relative thermal loading, $A$, can be found from:

$$
A=\frac{2 \times m \times W_{\Phi} \times I_{S H}}{\pi \times D_{a} \times \Phi} \times q 1 .
$$

In the above formula, $m$ is the number of stator phases; $q^{\prime}$ is the preliminary overall wire cross-section in slot; $D_{a}$ is the internal diameter of the stator; $W_{\Phi}$ is the number of turns per phase; and $I_{S H}$ is the current of a single stator section. The given set of parameters produces the value of $A=4.12 \mathrm{~A} / \mathrm{mm}^{2}$.

Knowing the section current and current density allows for the calculation of a crosssection of wire as:

$$
q_{a}=\frac{I_{S H}}{j_{S}}
$$

which, for this particular set of parameters, gives the value of $2.46 \mathrm{~mm}^{2}$.

The next step is the selection of the diameter of the insulated wire, $d_{a i}$, as well as the diameter of the wire without insulation, $d_{a}$. In the given design, $d_{a}=1.828 \mathrm{~mm}$, and $d_{a i}$ is $1.934 \mathrm{~mm}$, respectively. Knowing these diameters allows for the calculation of the cross-section area of the insulated wire as:

$$
q_{a i}=\frac{\pi \times d_{a i}^{2}}{4}
$$

which, in the given design, is equal to $2.94 \mathrm{~mm}^{2}$.

In the next step, the cross-section area of the stator slot can be found as:

$$
Q_{s l}=\frac{W_{\Phi} \times q_{a i} \times 10^{-6}}{p \times q \times k_{w i}},
$$


where $q$ is the number of slots per each pole and each phase; and $k_{w i}=0.28 \ldots 0.42$ density of winding in the slot, taking into account wire insulation. In the considered design, $Q_{s l}=78.5 \mathrm{~mm}^{2}$. The initial evaluation of the various slot profiles, such as O-shaped, Ushaped, and trapezoidal, in some others, gave the preference for semi-closed O-shaped (oval) slots with explicit coil windings (Figure 5).

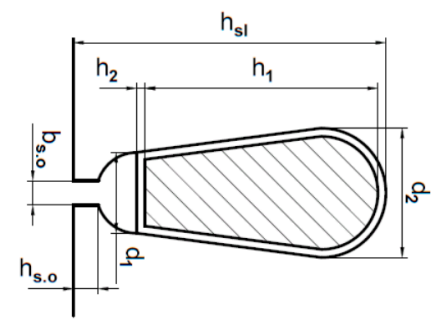

(a)

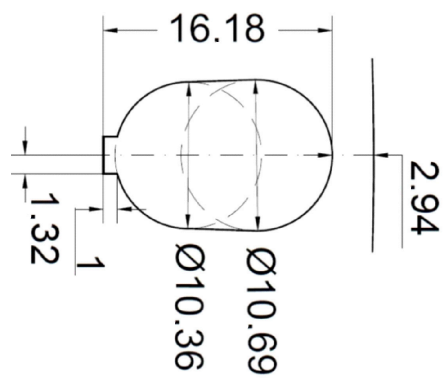

(b)

Figure 5. O-shaped (oval) slots for single section of modular sectional motor: (a) dimension units; (b) slot in scale with dimension.

In Figure $5, d_{1}$ is the diameter of the smaller rounding of the nonsymmetrical oval slot, and $d_{2}$ is the diameter of its larger rounding. Then, $b_{s . o}$ is the width of the opening of the slot, and $b_{s . o}$ is its length. In turn, $h_{s l}$ is the total height of the slot, $h_{2}$ is the thickness of the slot insulation, and $h_{1}$ is the height of the winding. The smaller and larger rounding diameters can be expressed as:

$$
\begin{gathered}
d_{1}=\frac{\pi \times\left(D_{a}+2 \times h_{s . o}\right)-z \times b_{s}}{z-\pi} \\
\text { and } d_{2}=\sqrt{\frac{4 \times Q_{s l}+d_{1}^{2} \times(z-\pi / 2)}{z+\pi / 2}} .
\end{gathered}
$$

For the considered parameters, $d_{1}=10.36 \mathrm{~mm}$, and $d_{2}=10.69 \mathrm{~mm}$. In turn, the height of the slot can be found as:

$$
h_{s l}=\frac{z \times\left(d_{1}-d_{2}\right)}{2 \pi}+\frac{d_{1}+d_{2}}{2}+h_{\text {s.o }}
$$

that produces the value of $16.18 \mathrm{~mm}$. Finally, the thickness of the insulation material, Isoflex ${ }^{\circledR}$, is equal to $0.35 \mathrm{~mm}$, and the length of the slot opening, $h_{s . o}$, has to be comparable with its width (1 $\mathrm{mm}$ is chosen), which can be found as:

$$
b_{\text {s.o }}=d_{a i}+2 h_{2}+0.0002
$$

which, in the given design, produces $0.00264 \mathrm{~m}$.

As is shown in $[17,18]$, in electrical motors with open slots, the value of the cogging torque may rise to up to $20 \%$ of its useful torque, but in the machines with the semi-open slots, it may rise to up to $11 \%$. The number of slots, 90 and 72 poles, in conjunction with $q=0.42$, gives the value of the cogging torque of $7 \%$.

The external diameter of the stator is located at $h_{a}$ of the larger rounding of the slots. This value can be found as:

$$
h_{a}=\frac{\Phi}{2 \times B_{a} \times l_{\delta} \times K_{F e}},
$$


where $B_{a}$ is the density of the magnetic flux in the larger rounding of the slot; and $k_{F e}$ is the density of the steel in the anchor package (in the given design $0.0043 \mathrm{~m}$ ). Then, the external diameter of the stator can be found as:

$$
D_{s}=D_{a}+2 \times\left(h_{s l}+h_{a}\right)
$$

which produces $0.4325 \mathrm{~m}$ in the given design.

The above-presented considerations allow for the detained analysis of the parameters of the stator windings, which are important for the power calculations.

\section{Arrangement of Basic Motor Elements and Prototype Layout}

In order to provide testing of the motor under variable loads, the motor was installed in the dedicated test bench (Figure 6a) and equipped with a braking/loading device. An alternative motor was installed in the prototype of the armrest modules (Figure 6b).

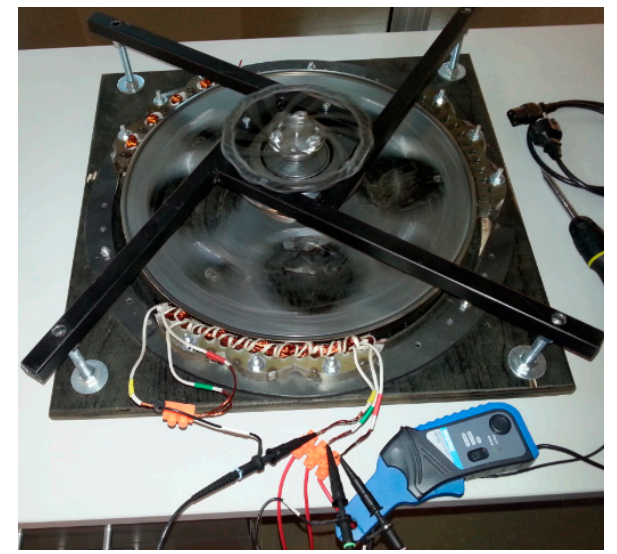

(a)

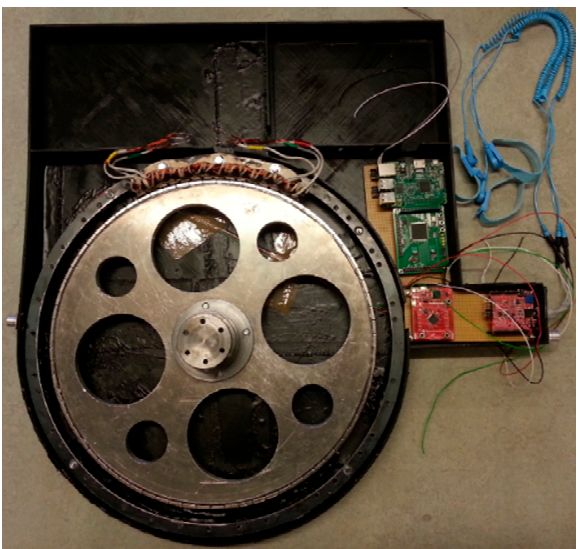

(b)

Figure 6. Evaluation of segmented motor: (a) test bench for motor loading and measurements, (b) prototype wheelchair armrest module with installed motor.

The sides of the console, referred to here, include the inner edge of the console (wall), that is, the edge closest to the seat, and the outer edge of the console (wall), that is, the edge facing outwards. The outer edge of the console is removable and provides access to the console cavity where the drive components are located. The braking device is located further from the outer edge of the console. The braking device consists of a disc brake on the disc, and a brake caliper with pads. The brake disc is located between the console and the wheel. The rim is located on the outside of the wheel and is intended to be powered by a human arm, as in typical with manual wheelchairs. The rotor of the motor was designed with a wheel hub without bearings, and with a shaft and attachment point with six screws for the further adaption of the spoke wheel (Figure 7a). A brake disc was installed between the motor shaft and the wheel hub. The motor shaft is mounted on two bearings. The motor bearings are located on the inner and outer edges of the console. The outer edge of the bearing has an inside diameter that is larger than the diameter of the brake disc mount. This allows for the removal of the outer edge of the console without removing the motor rotor. The rotor is made of an aluminum disc with permanent magnets attached to the edges. It is fixed to the motor shaft with four screws. The edges of the shaft are located in the bearings. The bearings are located on the reinforced edge parts. The stator (Figure $7 \mathrm{~b}$ ) motor parts are mounted on a specially prepared ring. The stator ring is made with threaded holes for the mounting of the motor prototype segments (Figure 7c). 


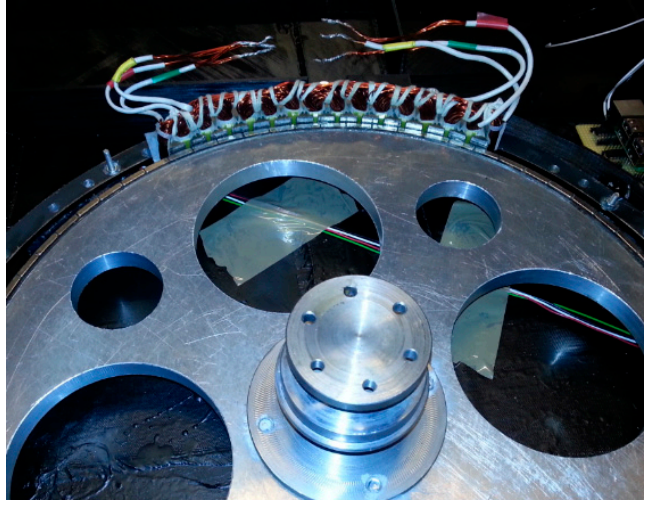

(a)

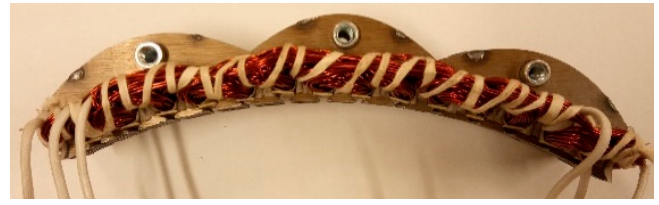

(b)

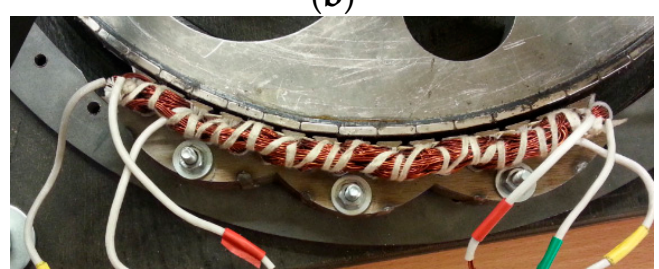

(c)

Figure 7. Details of evaluative design of segmented motor: (a) wheel shaft and motor rotor, (b) sole segment, (c) fastening of segment.

\section{Evaluation of Parameters of Segmented PMSM}

\subsection{Magnetic Parameters}

In order to verify if the stator segment is designed properly, from the point of view of the distribution of the magnetic field, the segment was simulated with the help of an FEM tool. A segment element modeling process permanent magnet measuring the flux density, and the electrical steel M250-35A parameters, was used. The corresponding dimensions of the segment are given in Figure 8a, the numbering of the slots in Figure 8b, and the allocation of the winding in Table 2. For the chosen winding, numerical modeling was provided with the help of QUICKFIELD software. The results of the modeling are presented in Figure 8c,d. It was concluded that the near sinusoidal three-phase distribution with a 120-degree sector had an amplitude difference of not more than $5 \%$ (due to border teeth magnetic field influence).

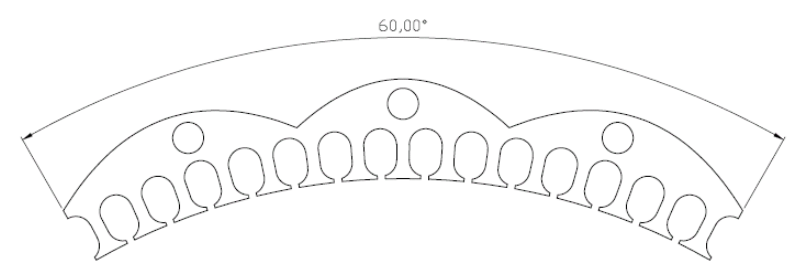

(a)

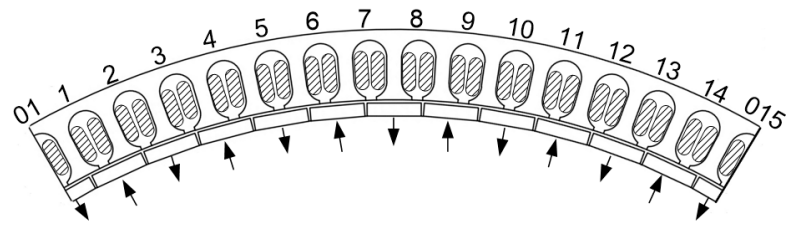

(b)

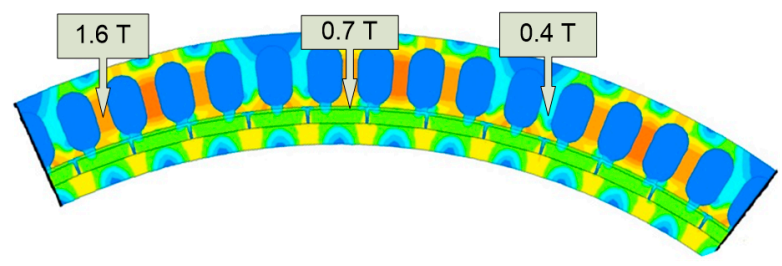

(c)

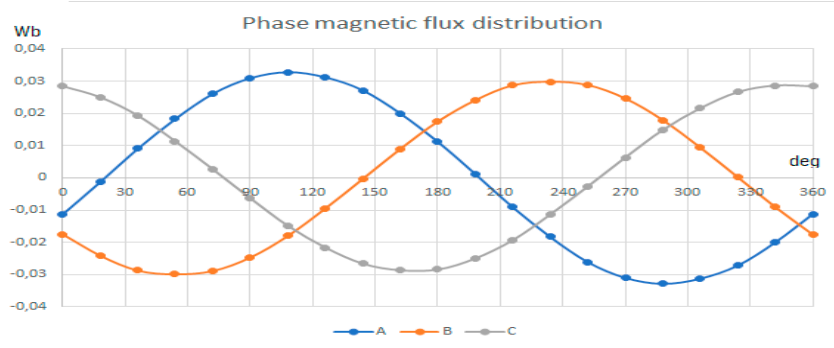

(d)

Figure 8. Model and FEM simulation of motor segment: (a) segment dimensions, (b) winding details, (c) results of FEM simulation, (d) phase magnetic flux distribution in one arc-shaped element. 
Table 2. Armature Winding Coil to Slot Arrangement.

\begin{tabular}{ccccccc}
\hline \multirow{2}{*}{ Coil } & \multicolumn{2}{c}{ Phase A } & \multicolumn{2}{c}{ Phase B } & \multicolumn{2}{c}{ Phase C } \\
\cline { 2 - 7 } & In & Out & In & Out & In & Out \\
\hline 1 & 4 & 5 & 2 & 3 & 01 & 1 \\
2 & 6 & 7 & 5 & 6 & 1 & 2 \\
3 & 9 & 10 & 7 & 8 & 3 & 4 \\
4 & 12 & 13 & 10 & 11 & 8 & 9 \\
5 & 14 & 15 & 13 & 14 & 11 & 12 \\
\hline
\end{tabular}

\subsection{Electrical Parameters}

The values of the main electrical parameters were extracted from the corresponding direct electrical measurements.

\subsubsection{Stator Phase Resistance $R_{S}$}

This parameter was calculated based on the measurements from the high-precision micro-ohmmeter METREL ${ }^{\circledR}$ MI 3252, used in conjunction with an RLC bridge and volt/ ampere meters, and combined together by means of the compensating four-wire connection. The following values of the phase resistance have been found for a single module: $R_{s, \bmod , A}=0.0679 \Omega ; R_{s, m o d, B}=0.0854 \Omega ; R_{s, \text { mod }, C}=0.0705 \Omega$; and their average value was $R_{s, \text { mod }}=0.0746 \Omega$. Then, based on the methodology from [19], the stator phase resistance $R_{S}$ is found as:

$$
R_{s}=k_{\theta} \times \frac{W_{f} \times l_{v}}{57 \times q_{a}},
$$

where $W_{f}$ is the number of turns in the phase coils; $l_{v}$ is the length of each turn; $q_{a}$ is the cross-section area of the wire utilized in the stator coils; and $k_{\theta}$ is the resistance temperature coefficient suitable to a temperature rise from $20{ }^{\circ} \mathrm{C}$ to the highest allowable operation temperature, $t_{\text {lim }}$, which can be found as:

$$
k_{\theta}=1+0.004 \times\left(t_{\text {lim }}-20\right) .
$$

Equation (19) is applicable to the whole stator. Applying it to a single arc-shaped segment requires division by six (the number of stator arc-shaped segments in this design). The calculated value of stator phase resistance for one arc-shaped module was $R_{s, \text { mod }}=0.0685 \Omega$.

The difference in the values of the stator phase resistance is also confirmed by the thermal test. A thermal image was taken while the windings were supplied from the same voltage source. The thermal image shows a $\pm 5^{\circ} \mathrm{C}$ temperature difference on the segment windings. The difference in temperature serves as an indicator of the actual differences in the resistance of the windings. The reason for this difference is the uneven implementation of the windings caused by occasional factors. This undesirable phenomenon will be minimized in future industrial designs while, in the given proof of concept work, it can be considered as acceptable.

\subsubsection{Stator Phase Inductances $L_{d}$ and $L_{q}$}

The procedure for the calculation of the stator phase inductance based on experimental measurements, provided in $[19,20]$, is known as the current step response test. It is based on the measurements of the stator current after the step changes of the corresponding stator DC voltage. The time constant of this process is obtained directly from the current waveform. In turn, the values of the inductance can be calculated based on the time constant. The step response test has to be repeated twice, with different positions of the rotor, in order to find the constants, $\tau_{e l, d}$ and $\tau_{e l, q}$. Then, the stator phase inductances can be calculated as:

$$
L_{d}=\tau_{e l, d} \times R \text { and } L_{q}=\tau_{e l, q} \times R .
$$


For the developed segment of the motor (Figure $7 \mathrm{~b}$ ), this method produces the values $L_{d}=0.000183 \mathrm{H}$, and $L_{q}=0.000177 \mathrm{H}$. It can be observed that $L_{d} \approx L_{q}$ is typical for SM PMSMs. The stator phase inductances, $L_{d}$ and $L_{q}$, can also be determined analytically. The calculation procedure, well-stated in [21], hereby is presented in a single equation from:

$$
\begin{gathered}
L_{d}=\frac{3}{\pi} \times\left(q \times n_{s} \times k_{w 1}\right)^{2} \times \frac{\mu_{0}}{\delta_{e}+\frac{l_{m}}{\mu_{r}}} \times\left(D_{a}-\delta\right) \times l \\
\text { and } L_{q}=\frac{3}{\pi} \times\left(q \times n_{s} \times k_{w 1}\right)^{2} \times \frac{\mu_{0}}{\delta_{e}+l_{m}} \times\left(D_{a}-\delta\right) \times l,
\end{gathered}
$$

where $n_{s}$ is the number of wires in a single stator slot; $k_{w 1}$ is the correction coefficient of the first harmonic; $\mu_{0}$ is the magnetic permeability of the vacuum $4 \pi \times 10^{-7} \mathrm{Vs} / \mathrm{Am} ; \mu_{r}$ is the magnetic permeability of the magnets; $\delta_{e}$ is the cumulative equivalent length of the air gap; $l_{m}$ is the magnet thickness; $D_{a}$ is the internal diameter of the stator; $\delta$ is the actual length of the air gap; and $l$ is the lamination of length. The values of the calculated stator inductances of the developed segment of the motor $\left(L_{d}=0.000192 \mathrm{H}\right.$ and $\left.L_{q}=0.000185 \mathrm{H}\right)$ are close to those that are found experimentally. In addition, (21) and (22) show that the stator inductances, $L_{d}$ and $L_{q}$, are proportional to the lamination of length and the quantity of the conductors in slots in power two. On the other hand, the quantity of segments has no influence of these parameters.

\subsection{Mechanical Parameters and Power}

In order to simplify the process of the experimental evaluation, the developed segmented motor has been supplied from a laboratory hardware-in-the-loop module "COMPISO P-HIL" (Figure 9). The voltage and current meters were attached to record the corresponding rms values. In turn, an oscilloscope has been utilized to detect the phase shift between the voltage and the current. During the experiment, the motor was loaded by a mechanical breaker, while the rpm was fixed by a contact element.
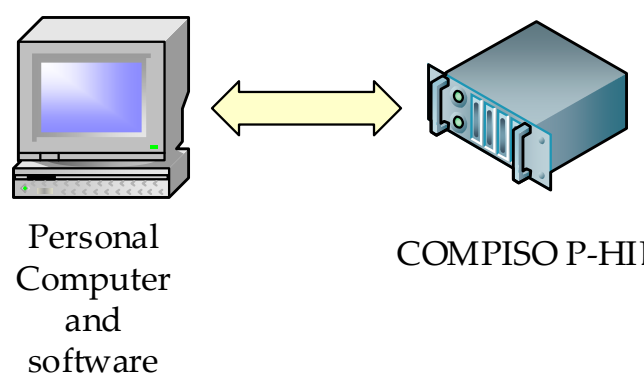

and

\section{COMPISO P-HIL}

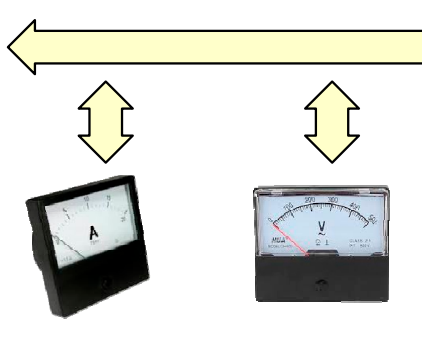

Voltage and current meters

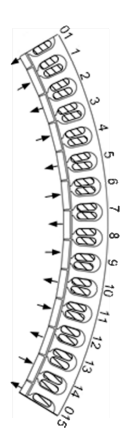

Figure 9. Functional diagram of experimental setup.

The evaluation of the cogging torque is one of the quality-defined parameters for PMSMs. The typical methods for reducing the cogging effect are based on the magnet shift method [22], slot skewing [23,24], pole-arc optimization, slot shifting, etc. [25,26].

For the evaluation of the cogging torque and the torque ripple effects, the calculation of the whole machine, and the calculation of the individual arc-shaped stator element (Table 3) were applied. Parts of the motor were rated using the same formulas. For ease of representation, the arc-shaped stator elements were considered as a whole machine. 
Table 3. Motor and Segment Data.

\begin{tabular}{ccc}
\hline & Motor & Segment \\
\hline$N_{s}$ & 90 & 15 \\
$N_{m}$ & 72 & 12 \\
$N_{s p p}$ & 0.42 & 0.42 \\
$a_{s k}$ & 0.25 & 0.25 \\
$n_{\text {cog }}$ & 5 & 5 \\
\hline
\end{tabular}

Note that the number of poles of magnets, $N_{m}$, the number of slots in the stator, $N_{s}$, and the number of slots per each pole and per each phase, $N_{s p p}=N_{s} / N_{m} / N_{p h}$, are taken as table quantities. The minimum skew required to eliminate cogging torque, $a_{\mathrm{sk}}$, is given in terms of slot pitches:

$$
\alpha_{s k}=\frac{N_{s}}{\operatorname{LCM}\left(N_{s}, N_{m}\right)} .
$$

In (23), $\operatorname{LCM}\left(N_{s}, N_{m}\right)$ is the least common multiple of the number of stator slots $N_{s}$ and the number of rotor magnetic poles $N_{m}$. Note that the lowest acceptable value of the skew, provided by a combination of mechanical factors, ensures only minimal equalizing of the magnetic flux and results in back electromotive force.

In the motors of small axial length, significant skew is not realistic. Then, the cogging torque can be estimated based on the index, $n_{\text {cog }}$. For the motors with the integer ratio $q=N_{s} / N_{m}$, this index, expressing the weight of the first harmonic of the cogging torque, is found as $n_{c o g}=q$. For motors with the fractional ratio, $q=N_{s} / N_{m}$, without the common factors of $N_{s}$ and $N_{m}$, this index is expressed as $n_{\operatorname{cog}}=N_{s}$. Finally, if $q=N_{s} / N_{m}$ is fractional, and if the greatest common divisor of $N_{s}$ and $N_{m}$ is an integer number, $v$, this index is $n_{c o g}=N_{s} / v$, expressing certain spatial periodicity.

This consideration is correct for the whole rotor motor or for the one arc-shaped element (segment). Installing several arc-shaped elements allows for a reduction in the cogging effect by means of the dedicated displacement of these elements. This feature has been studied with two arc-shaped elements.

Figure 10a shows the cogging torque for three occasions. The cogging torque of a single segment has pulsating characteristics with a maximum value of $0.34 \mathrm{Nm}$. The addition of the second arc-shaped segment at the exact symmetric position after 60, 120, or 180 geometrical degrees, without extra displacement, just increases this cogging effect. This influence is nonlinear and, in this case, the maximum value was $0.42 \mathrm{Nm}$.

Utilizing the free placement approach of the second element smooths the cogging effect. If the second element is located with an extra displacement of $1 / 2$ of the permanent magnet pole zone, which for the designed example is a 2.5 geometrical degree (that together gives 62.5 degrees), the cogging effect is decreased to $0.16 \mathrm{Nm}$, and the pulsating frequency is increased. The discovered method is suitable on modular motors for reducing cogging torque.

The experimental motor form was tested under several load values. The results of testing are presented in Table 4 . The motor was tested at an industrial frequency, $50 \mathrm{~Hz}$, with a sinusoidal voltage (AC $24 \mathrm{~V}_{\mathrm{rms}}$ ) form. At this condition, the synchronous speed of the motor was $n_{\text {rated }}=83^{1} / 3 \mathrm{rpm}$. The main testing task was to evaluate the rated parameter of motor dependence from the number and placement of the arc-shaped elements. 


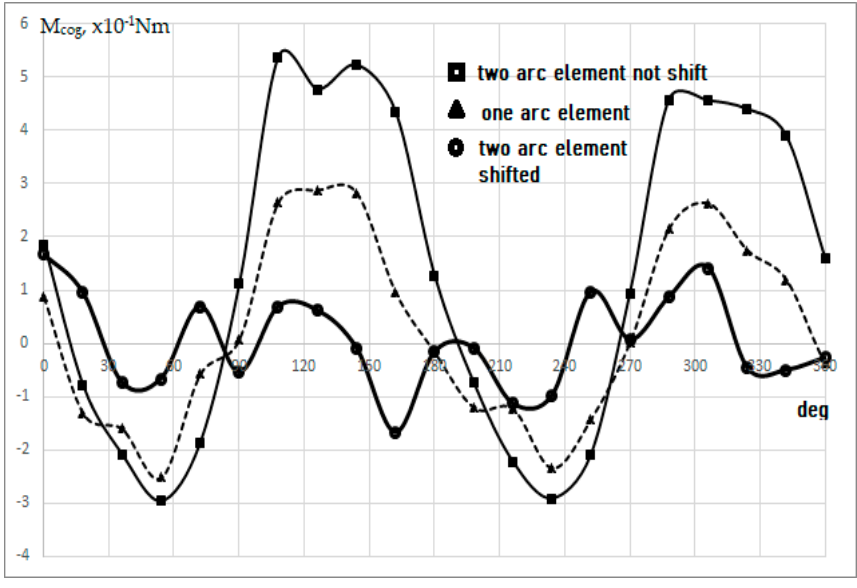

(a)

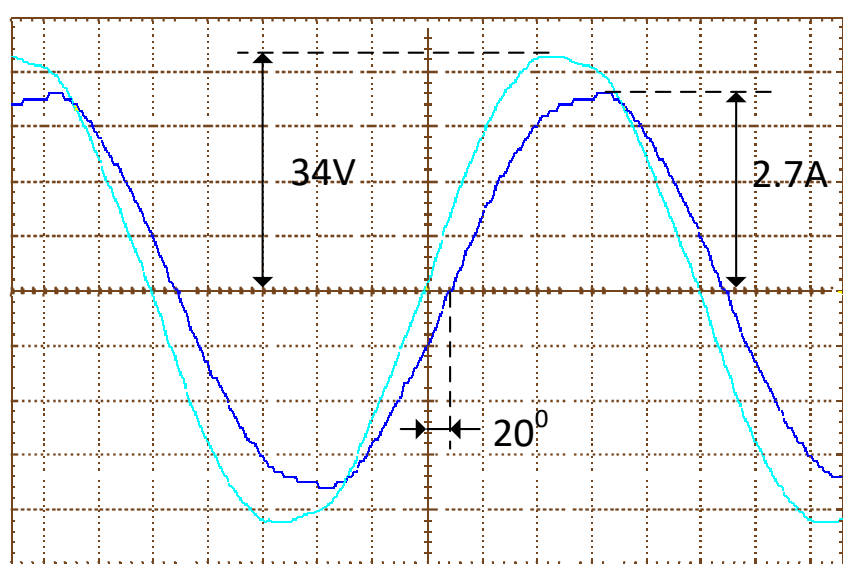

(b)

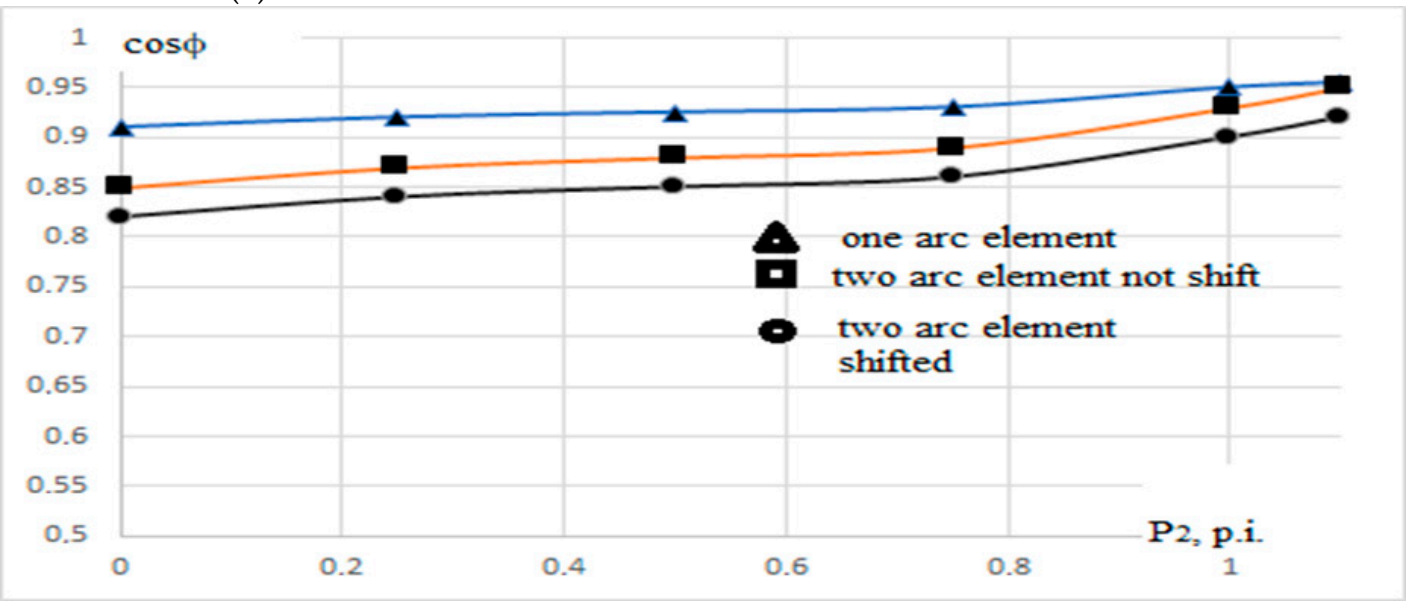

(c)

Figure 10. Results of tentative experimental evaluation of the developed segmented motor: (a) cogging moment dependence from rotational angle for one and two arc-shaped elements with shift angle, (b) instantaneous voltage and current of a single arc-shaped segment at rated parameters, (c) power factor as a function of motor load.

Table 4. Numerical Test Results of Motor Segments.

\begin{tabular}{cccccc}
\hline Segments & $\boldsymbol{M}_{\text {load }}[\mathbf{N m}]$ & $\boldsymbol{I}[\mathrm{A}]$ & $\cos \boldsymbol{\phi}$ & $\boldsymbol{\eta}$ & $\boldsymbol{P}_{\text {segm }}[\mathbf{W}]$ \\
\hline 1 & 3.9 & 1.9 & 0.95 & 0.75 & 57 \\
2 (no shift) & 8.1 & 4.3 & 0.94 & 0.71 & 117 \\
2 (shifted) & 8.2 & 4.2 & 0.92 & 0.74 & 119 \\
\hline
\end{tabular}

After the obtained data evaluation at load moment with one arc-shaped element, the motor efficiency was found to be higher in comparison with the two arc-shaped elements. The cogging effect, which reduced the displacement of the arc-shaped elements given at load moments, reduced in a similar way to other arc-shaped elements.

The Table 4 parameters, such as mechanical load, $M_{\text {load }}$, and armature current, $I$, are measured providing experiments. Experimentally, $\cos \varphi$ was obtained from an oscilloscope measurement as the current-voltage shift (Figure 10b). The efficiency factor is calculated as:

$$
\eta=\frac{P_{2}}{P_{1}} .
$$

The shaft mechanical power calculated is:

$$
P_{2}=\frac{2 \pi}{60} M_{\text {load }} n_{\text {rated }}
$$


With a fixed supply of voltage and frequency, measurements were taken of the power factor $(\cos \varphi)$ for three variants of arc-shaped element displacement. The obtained data are presented in Figure 10c.

As can be concluded, based on the data from Figure 10b,c, the motor excitation field of the permanent magnets produces over-excitation. This mode of electrical machine produces a curve view with a growing power factor. After analyzing this motor mode, the authors concluded that permanent magnet magnetic flux can be decreased, and that there are other opportunities to increase the rated power of the arc-shaped element.

\subsection{Thermal Considerations}

The initial structure of this evaluative work did not assume any thermal considerations. However, the lower obtained energy efficiency, in conjunction with the complicated operation conditions (closed environment, other electrical equipment with their own losses), caused the authors to evaluate this thermal behavior too.

An experiment was carried out in order to determine the operating time of one segment during overload, which may occur regularly in the considered application. The conditions for the experiment are defined as the triple overload of the segment, assuming that two of the three installed segments are broken. This mode is characterized by an increased winding current and power losses that lead to serious overheating $\left(142{ }^{\circ} \mathrm{C}\right.$ in Figure 11a). Moreover, Figure $11 \mathrm{~b}$ shows that the temperature, within about $15 \mathrm{~min}$, does not reach its stationary value. This, in turn, means that the motor may be overheated, even at the rated current (but after a longer time) that requires the use of insulation class $\mathrm{F}$ $\left(155^{\circ} \mathrm{C}\right)$.

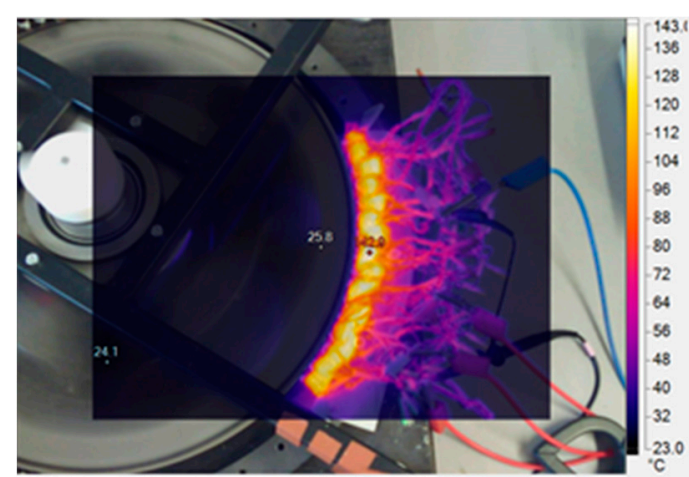

(a)

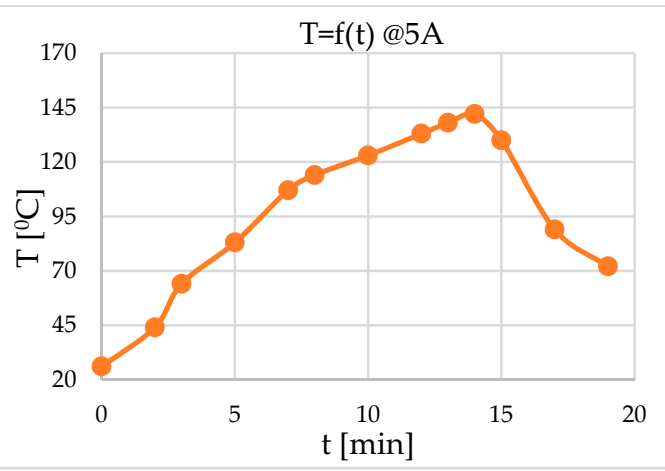

(b)

Figure 11. Heating process of segment: (a) IR Image at 14 min of 3xIn load, (b) characteristic of winding temperature on its surface.

The above-described experiment proves that particular attention has to be paid to the cooling system. Taking into account the closed operation environment, and its distant location from convenient cooling places (under the seat of the wheelchair or on the outer surfaces of armrest modules [7]), a potential solution could be a loop heat pipe with a nonrigid connection between the evaporator and the condenser.

\section{Discussion and Conclusions}

The collected simulation and experimental data prove the feasibility of a multiple motor drive with the help of a single electromechanical unit. The approach provides a lower weight and price, keeping the reliability and torque at the necessary level due to the cancelling of unnecessary power. It makes it suitable for use in light electric vehicles, in which maximal power must be tuned depending on the different conditions together with the overall price; for example, as for the power assist wheelchair, where the degree of drive assistance depends on the needs of the user. 
Additionally, the proposed approach allows for the reduction of the cogging effect, which may make the wheelchair unpleasant to use. Applying the modular design method when the stator is not completely filled with segments for full-rated power, the method described in this article allows for the reduction in the cogging effect by $50 \%$ in comparison with the one arc-shaped element adding one more segment. The proposed method for cogging effect reduction starts to work within two allocated segments, and reaches maximal effect at segments completely filled for full-rated power.

The segmented structure of the motor, presented in this paper, is also applicable to other types of motors; however, a permanent magnet motor was chosen for this proof of concept. The choice was based on the simple, easily implementable motor construction, and on the variety of applicable test equipment, including simple laboratory generators and adjustable transformers, as well as on the better dynamic performance in terms of the rapid changes in the control signals, making the wheelchair more maneuverable. On the other hand, the segmented asynchronous machine could provide better starting torque. In turn, the switched reluctance machine could be cheaper because of the absence of magnets, but more efficient than the asynchronous one. Both of these alternatives, as well as some others, provide lower costs for the motor and are worth considering in future works. below:

Other future works that might address the development of the concept are listed

(1) It is necessary to develop the design methodology for modular segmented motors, to bring forward parameter calculation procedures, and to clarify the design fitting to particular applications.

(2) It is also important to improve the energy efficiency of the motor (the achieved one is $75 \%$, that is not much, even for low power motors). First of all, the efficiency of the motor, composed of three, four, five, and six segments, has to be evaluated while the motor losses have to be allocated. Then, the proposals for efficiency improvement have to be brought forward.

(3) As was concluded in Section 5.4, this particular motor also has cooling problems. Even at higher energy efficiency, the power losses of the motor $(5 \ldots 10 \%$ of 300 $\mathrm{W}$, which is $15 \ldots 30 \mathrm{~W}$ )) in closed operation environments may lead to significant overheating. At the same time, the obviously distant location of the segments and cooling elements requires the use of a sophisticated cooling system, for example, a loop heat pipe with an elastic connection between the evaporator and the condenser. This work is another potential extension of this research.

(4) At last, it is necessary to develop the power electronic driver and its control unit for the motor and the drive, as well as to study the obtained segmented drive on the whole.

Author Contributions: Conceptualization, I.A.G.; Methodology, A.P. and I.A.G.; Software, R.G.; Validation, I.A.G., R.G. and A.P.; Formal Analysis, A.P.; Investigation, R.G.; Resources, I.A.G.; Writing—original draft preparation, I.A.G. and A.P.; Writing—review and editing, I.A.G.; Visualization, R.G.; Supervision, I.A.G.; Project Administration, I.A.G. All authors have read and agreed to the published version of the manuscript.

Funding: This research was funded by the European Regional Development Fund (ERDF) within the contract Nr. 1.1.1.1/16/A/147, "Research and Development of Electrical, Information and Material Technologies for Low Speed Rehabilitation Vehicles for Disabled People", and by the Latvian Council of Science project, "Enhanced Thermal Management of Electric Drives in Orthopedic Rehabilitation Vehicles for their Better Reliability and Functionality", project No. lzp-2020/2-0390.

Institutional Review Board Statement: Not applicable.

Informed Consent Statement: Not applicable.

Data Availability Statement: Data is contained within the article.

Conflicts of Interest: The authors declare no conflict of interest. 


\section{References}

1. European Commission. A Clean Planet for all. A European long-term strategic vision for a prosperous, modern, competitive and climate neutral economy. Com 2018, 773, 114.

2. Delhi, S.I.N. Automotive Revolution \& Perspective towards 2030. Auto Tech. Rev. 2016, 4, 20-25.

3. Sarlioglu, B.; Morris, C.T.; Han, D.; Li, S. Driving Toward Accessibility: A Review of Technological Improvements for Electric Machines, Power Electronics, and Batteries for Electric and Hybrid Vehicles. IEEE Ind. Appl. Mag. 2017, 23, 14-25. [CrossRef]

4. Rastogi, S.K.; Sankar, A.; Manglik, K.; Mishra, S.K.; Mohanty, S.P. Toward the Vision of All-Electric Vehicles in a Decade [Energy and Security]. IEEE Consum. Electron. Mag. 2019, 8, 103-107. [CrossRef]

5. Bertoluzzo, M.; Buja, G. Development of electric propulsion systems for light electric vehicles. IEEE Trans. Ind. Inform. 2011, 7, 428-435. [CrossRef]

6. Electric Vehicle Database, Hyundai Kona Electric. Available online: https:/ / ev-database.org/car/1239/Hyundai-Kona-Electric39-kWh (accessed on 5 October 2021).

7. Galkin, I.; Podgornovs, A.; Blinov, A.; Vitols, K.; Vorobyov, M.; Kosenko, R. Considerations regarding the concept of cost-effective power-assist wheelchair subsystems. Electr. Control Commun. Eng. 2018, 14, 71-80. [CrossRef]

8. Galkin, I.; Blinov, A.; Verbytskyi, I.; Zinchenko, D. Modular self-balancing battery charger concept for cost-effective power-assist wheelchairs. Energies 2019, 12, 1526. [CrossRef]

9. World Report on Disability 2011; World Health Organization: Geneva, Switzerland, 2011; pp. 1-350.

10. Kraus, L.; Lauer, E.; Coleman, R.; Houtenville, A. 2017 Disability Statistics Annual Report: A Publication of the Rehabilitation Research and Training Center on Disability Statistics and Demographic; Univ. NH New Hampshire: Durham, NH, USA, 2018.

11. Disability Statistics. Eurostat Statistics Explained. 2019. Available online: https://ec.europa.eu/eurostat/statistics-explained/ index.php/Disability_statistics (accessed on 21 August 2019).

12. Dudgeon, B.J.; Deitz, J.C.; Dimpfel, M. Wheelchair Selection. In Occupational Therapy for Physical Dysfunction; Wolters Kluwer Health/Lippincott Williamns \& Wilkins: Philadelphia, PA, USA, 2013.

13. Ding, D.; Cooper, R.A. Electric-Powered Wheelchairs. IEEE Control Syst. Mag. 2005, 25, 22-34.

14. Hou, R.; Shi, X.; Krishnamurthy, M. Design and implementation of a novel power assisted drivetrain for a wheelchair. In Proceedings of the 2012 IEEE Transportation Electrification Conference and Expo (ITEC), Dearborn, MI, USA, 18-20 June 2012; pp. 1-6.

15. Yang, Y.-P.; Lin, H.-C.; Tsai, F.-C.; Lu, C.-T.; Tu, K.-H. Design and integration of dual power wheels with rim motors for a powered wheelchair. IET Electr. Power Appl. 2012, 6, 419. [CrossRef]

16. Jajtic, Z.; Ulmar, E.; Volmert, C.; Fretzscner, S.; Pommer, H.; Dorfner, M. Segmented electric machine-Modular motor and system topology for direct drives. In Proceedings of the 2011 1st International Electric Drives Production Conference, Nuremberg, Germany, 28-29 September 2011; pp. 36-39.

17. Salminen, P.; Niemelä, M.; Pyrhönen, J. Performance analysis of fractional slot wound PM-motors for low speed applications. In Proceedings of the Conference Record of the 2004 IEEE Industry Applications Conference, Seattle, WA, USA, 3-7 October 2004. [CrossRef]

18. Salminen, P. Fractional Slot Permanent Magnet Synchronous Motors for Low Speed Applications. Ph.D. Thesis, Lappeenranta University of Technology, Lappeenranta, Finland, 20 December 2004.

19. Lifanov, V.A. Calculation of Low-Power Electric Machines with Excitation from Permanent Magnets: A Tutorial; Chelyabinsk Publishing Center: Chelyabinsk, Russia, 2010; p. 164. (In Russian)

20. Hanselman, D. Brushless Permanent Magnet Motor Design; Magna Physics Publishing: Lebanon, OH, USA, 2006.

21. Meier, S. Theoretical Design of Surface-Mounted Permanent Magnet Motors with Field-Weakening Capability. Master's Thesis, Royal Institute of Technology, Stockholm, Sweden, 2002.

22. Bianchi, N.; Bolognani, S. Design techniques for reducing the cogging torque in surface-mounted PM motors. IEEE Trans. Ind. Appl. 2002, 38, 1259-1265. [CrossRef]

23. Fei, W.; Zhu, Z.Q. Comparison of cogging torque reduction in permanent magnet Brushless machines by conventional and herringbone skewing techniques. IEEE Trans. Energy Convers. 2013, 28, 664-674. [CrossRef]

24. Lukaniszyn, M.; JagieLa, M.; Wrobel, R. Optimization of permanent magnet shape for minimum cogging torque using a genetic algorithm. IEEE Trans. Magn. 2004, 40, 1228-1231. [CrossRef]

25. Liu, T.; Huang, S.; Gao, J.; Lu, K. Cogging torque reduction by slot-opening shift for permanent magnet machines. IEEE Trans. Magn. 2013, 49, 4028-4031. [CrossRef]

26. Dosiek, L.; Pillay, P. Cogging torque reduction in permanent magnet machines. IEEE Trans. Ind. Appl. 2007, 43, 1565-1571. [CrossRef] 